\title{
Ameliorative potential of minocycline and/or lactulose on experimentally induced colitis
}

\author{
Ahmed Kabel ${ }^{1,2, a *}$ \\ ${ }^{1}$ Department of Pharmacology, Faculty of Medicine, Tanta University, Tanta, Egypt \\ ${ }^{2}$ Department of Clinical Pharmacy, College of Pharmacy, Taif University, Taif, Saudi Arabia \\ a drakabel@gmail.com \\ * Corresponding author: Dr. Ahmed M. Kabel, El-Geish street, Faculty of Medicine, \\ Tanta University, Department of Pharmacology, Tanta, Egypt; \\ E-mail: drakabel@gmail.com; Tel.:00201009041488; Postal code: 31527
}

Keywords: colitis; lactulose; minocycline; rats

\begin{abstract}
Objective: The aim of this study was to compare between the effect of minocycline or lactulose alone and in combination on experimentally-induced colitis in rats. Materials and methods: Seventy albino rats were divided into 7 equal groups: Control untreated group, trinitrobenzenesulphonic acid (TNBS) group, TNBS + lactulose group, lactulose group, TNBS + minocycline group, minocycline group and TNBS + lactulose+ minocycline group. A part of the colon was homogenized for determination of tissue tumor necrosis factor alpha, malondialdehyde, nitric oxide, reduced glutathione and myeloperoxidase. The other part of the colon was examined histopathologically. Also, disease activity index was measured. Results: Administration of each of lactulose or minocycline alone and in combination to TNBS- treated rats induced significant increase in tissue reduced glutathione with significant decrease in disease activity index, tissue tumor necrosis factor alpha, malondialdehyde, nitric oxide and myeloperoxidase and alleviated the histopathological changes compared to the group that received TNBS alone. Minocycline/lactulose combination produced significant improvement in the biochemical and histopathological parameters compared to the groups that received either minocycline or lactulose alone. Conclusion: Lactulose and minocycline had protective effects on TNBS-induced colitis in rats but minocycline/lactulose combination had the upper hand.
\end{abstract}

\section{Introduction}

Colitis is a form of inflammatory bowel diseases that includes characteristic ulcers or open sores. The main symptom of colitis is usually gradual onset of constant diarrhea mixed with blood. Colitis is an intermittent disease, with periods of exacerbated symptoms and periods that are relatively symptomfree [1]. Although the symptoms of colitis can sometimes diminish spontaneously, the disease usually requires treatment to go into remission. Although colitis has no known cause, there is a presumed genetic component to susceptibility. The disease may be triggered in a susceptible person by environmental factors [2]. Several studies reported that the increased production of proinflammatory cytokines such as TNF- $\alpha$ and interleukin 10 as well as oxidative stress may have an important role in the pathogenesis of colitis [3-5]. Colitis is treated as an autoimmune disease. Treatment is with anti-inflammatory drugs, immunosuppressive drugs and biological therapy targeting specific components of the immune response. Colectomy is occasionally necessary, but is not a cure for the disease [6].

Sulphasalazine is a sulfa drug that is formed by combining sulphapyridine and salicylate with an azo bond. It was developed specifically to treat rheumatoid arthritis because bacterial infections were believed to be the cause [7]. Sulphasalazine, and its metabolite 5-ASA, are poorly absorbed from the gut. In colitis, it is thought to be an antinflammatory drug that is essentially providing topical relief inside the intestine. However, it has many adverse effects which necessitate searching for alternative and adjuvant agents [8]. 
Lactulose is a synthetic, non-digestible sugar used in treatment of chronic constipation and hepatic encephalopathy. It is a disaccharide formed of fructose and galactose. It is produced commercially by isomerization of lactose [9]. It is digested by bacteria colonizing within the gastrointestinal tract, especially in the colon. Lactulose may be a novel and promising therapeutic option for colitis, possibly due to alterations of colonic microflora which are responsible for colonic inflammation [10]. Also, oral administration of lactulose significantly increased $\mathrm{H}_{2}$ production which may has antioxidant and anti-inflammatory properties in the gastrointestinal tract $[11,12]$.

Minocycline is a broad-spectrum bacteriostatic tetracycline antibiotic that has a crucial role in treatment of many bacterial infections. It has recently been reported to display immunomodulatory properties in addition to their antimicrobial activity. The use of a compound with both immunomodulatory and antibacterial properties could be very interesting in the treatment of colitis [13]. Also, minocycline was found to block the expression of inducible nitric oxide synthase and matrix metalloproteinases which play an important role in the pathogenesis of ulcerative colitis [14]. Moreover, minocycline was reported to have antioxidant and antiapoptotic properties that may provide beneficial effects in the treatment of colitis [15]. The aim of this study was to compare between the effect of minocycline or lactulose alone and in combination on experimentally-induced colitis in rats.

\section{Materials and methods}

\section{Materials}

Trinitrobenzenesulphonic acid (TNBS), lactulose, minocycline and all other chemicals were purchased from Sigma Chemical Co (St. Louis, MO, USA). All the materials in this study were endotoxin free. TNBS was dissolved in $30 \%$ ethanol in saline to produce a concentration of 40 $\mathrm{mg} / \mathrm{ml}$. Lactulose and minocycline were dissolved in distilled water. Doses of the drugs used in this study were selected according to previously published studies. ELISA kits were supplied by RayBiotech, Inc., USA for determination of TNF- $\alpha$.

Animals

The present study was carried out on seventy Sprague Dawley male rats weighing 150-200 grams collected from local source. Animals were kept in individual metabolic cages (Tecniplast, Varese, Italy) at $22{ }^{\circ} \mathrm{C}, 55 \%$ relative humidity, 12 hour light, with free access to food and tap water ad libitum through the whole period of the study. All the experiments were conducted according to the National Research Council's guidelines and were approved by the local ethics committee. Animal handling was followed according to Helsinki declaration of animal ethics.

Induction of colitis

Rats were anesthetized with $20 \%$ ethyl carbamate (intraperitoneal, $6 \mathrm{~mL} / \mathrm{kg}$ ) and $0.5 \mathrm{ml}$ of $30 \%$ ethanol-TNBS was slowly administered into the lumen of the colon via the anus using a rubber catheter (12 cm long, external diameter $2 \mathrm{~mm}$ ) [16].

Rats were divided into seven equal groups each of 10 rats as follows:

Group I: Untreated control group, received $0.9 \%$ saline administered through rectum as a single application through a rubber catheter.

Group II: Received TNBS-20 mg in $30 \%$ ethanol administered through rectum as a single application through a rubber catheter [8].

Group III: Received TNBS-20 mg in $30 \%$ ethanol rectally then received lactulose by oral gavage in a dose of $600 \mathrm{mg} / \mathrm{kg} /$ day for 7 days [9].

Group IV: Received lactulose by oral gavage in a dose of $600 \mathrm{mg} / \mathrm{kg} /$ day for 7 days [9].

Group V: Received TNBS-20 mg in $30 \%$ ethanol rectally then received minocycline by oral gavage in a dose of $40 \mathrm{mg} / \mathrm{kg} /$ day for 7 days [13].

Group VI: Received minocycline by oral gavage in a dose of $40 \mathrm{mg} / \mathrm{kg} /$ day for 7 days [13].

Group VII: Received TNBS-20 mg in $30 \%$ ethanol rectally then received minocycline/lactulose combination by oral gavage for 7 days (minocycline in a dose of $40 \mathrm{mg} / \mathrm{kg} /$ day and lactulose in a dose of $600 \mathrm{mg} / \mathrm{kg} /$ day). 


\section{Evaluation of colitis}

In order to determine the clinical activity of TNBS-induced colitis, rats were examined for stool consistency (loose stool, diarrhea), occult and/or bleeding (hemoccult positivity, gross bleeding) and body weight on daily basis after TNBS administration. The body weight was expressed as percentage weight change for each individual rat and was calculated compared with that on day 0 . These data were used to calculate a disease activity index (DAI) as described by Cooper et al. [17] (Table 1).

Table 1: Disease activity index score

\begin{tabular}{cccc}
\hline Score & Weight loss $(\%)$ & Stool consistency & Occult/gross bleeding \\
\hline 0 & None & Normal & Normal \\
1 & $1-5$ & & \\
2 & $5-10$ & Loose & Hemoccult positive \\
3 & $10-20$ & & \\
4 & $>20$ & Diarrhea & Gross bleeding \\
\hline
\end{tabular}

\section{Histopathological examination}

After 7 days from administration of TNBS, rats were killed then opened by midline laparotomy and the colon was longitudinally opened. A part of the colon was fixed with $10 \%$ neutral buffered formalin and embedded in paraffin. After deparaffinizing the thin tissue sections on glass slides, they were stained with hematoxylin and eosin $(\mathrm{H} \& \mathrm{E})$. The severity of colitis was assessed using a histological disease score described by Hirata et al. [18] (Table 2) and apoptotic indices were determined.

Table 2: Histological disease score

\begin{tabular}{ll}
\hline Grade 0 & Normal colonic mucosa \\
\hline Grade 1 & Loss of one-third of the crypts \\
\hline Grade 2 & Loss of two-thirds of the crypts \\
\hline Grade 3 & $\begin{array}{l}\text { The lamina propria is covered with a single layer of epithelium } \\
\text { and mild inflammatory cell infiltration is present }\end{array}$ \\
\hline Grade 4 & Erosions and marked inflammatory cell infiltration are present
\end{tabular}

Randomly selected 8 fields (magnified 100 times) in each section were inspected and graded as above by a pathologist who was blinded to the treatment protocol. The mean in each section was calculated by scoring the grades in 8 fields.

Apoptotic index (AI) was defined as aggregate percentages of apoptotic cells and/or apoptotic bodies per total number of cells (1000 cells counted) in 10 randomly selected high power fields $(\times 400)$. The counting was performed by one pathologist, and in $20 \%$ of randomly selected cases the counting was repeated by another pathologist. In cases with significant disagreement between results, the counting was performed at the multiheaded microscope by both pathologists. The morphological criteria for apoptotic bodies were applied in our study as follows : (1) a single rounded mass with condensed, strongly eosinophilic cytoplasm with a single clump of strongly basophilic material representing chromatin condensation; (2) similar to the previously mentioned structure but with condensed chromatin, fragmented into more than one piece; (3) fragments of condensed chromatin without surrounding cytoplasm. The apoptotic bodies most frequently appear as single structures separated from the surrounding intact cells by a clear halo. Clusters of minute apoptotic bodies were counted as one. Apoptotic bodies were not counted in necrotic areas. Equivocal apoptotic bodies were not counted. 
Assessment of the biochemical parameters

The other part of the colon was homogenized in 10 volumes of ice-cold $10 \%$ trichloroacetic acid and centrifuged at $3000 \mathrm{rpm}$ for $15 \mathrm{~min}$ at $4{ }^{\circ} \mathrm{C}$. The supernatant was removed and recentrifuged at $15000 \mathrm{rpm}$ at $4{ }^{\circ} \mathrm{C}$ for $8 \mathrm{~min}$. The resulting supernatant was used for determination of tissue reduced glutathione (GSH) level by a spectrophotometric method which is a modification of Ellman procedure [19], tissue malondialdehyde (MDA) level according to the method of Casini et al. [20], tissue myeloperoxidase (MPO) activity according to the method of Bradley et al. [21], tissue TNF- $\alpha$ using ELISA kits, tissue nitric oxide (NO) (Tissue nitrite and nitrate were estimated as an index of NO production) according to Cortas \& Wakid [22] and tissue total protein content according to the method of Lowry et al. [23].

Statistical analysis

Data were presented as mean \pm standard error of mean (SEM). Data were statistically analyzed by computer SPSS 15 software. Data were analyzed by one way analysis of normality of variance (ANOVA). Independent sample t-test and Covariate test were used as statistical tests. Differences between the means of different groups were considered significant at a level of $p$ value less than 0.05 .

\section{Results}

\section{Effect of different treatments on DAI}

Administration of TNBS to rats resulted in significant increase in DAI compared to the control untreated group. Administration of each of lactulose or minocycline to normal rats produced non-significant effect on DAI compared to the control untreated group. Administration of each of lactulose or minocycline to TNBS-treated rats induced significant decrease in DAI compared to the group that received TNBS alone. The decrease in DAI was significant in minocycline/lactulose combination group compared to the use of either minocycline or lactulose alone (Fig.1).

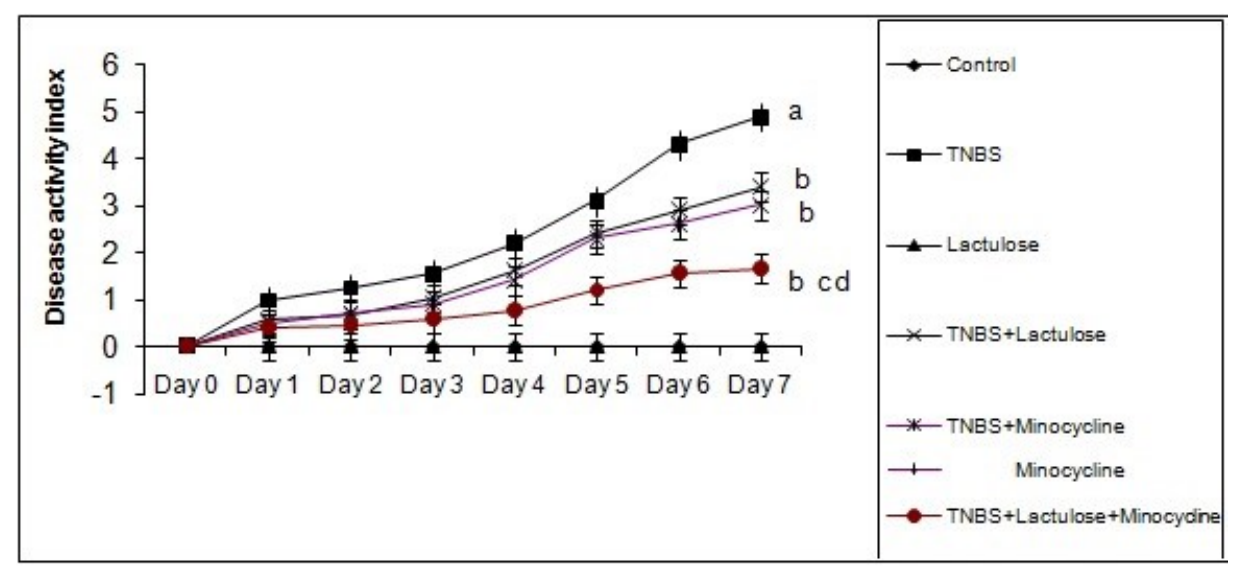

Fig. 1: Effect of different treatments on the disease activity index.

${ }^{\text {a }}$ Significant compared to the control group

${ }^{\mathrm{b}}$ Significant compared to TNBS group

${ }^{c}$ Significant compared to TNBS + lactulose group

d Significant compared to TNBS + minocycline group

\section{Effect of different treatments on the antioxidant status}

Administration of TNBS to rats resulted in significant increase in tissue MDA with significant decrease in tissue GSH compared to the control untreated group. Administration of each of lactulose or minocycline to normal rats produced non-significant effect on the antioxidant status compared to the control untreated group. Administration of each of lactulose or minocycline induced significant decrease in tissue MDA with significant increase in tissue GSH compared to the group that received TNBS alone. The increase in tissue GSH and the decrease in tissue MDA were significant in minocycline/lactulose combination group compared to the use of either minocycline or lactulose alone (Table 3). 


\section{Effect of different treatments on tissue TNF- $\alpha$}

Administration of TNBS to rats resulted in significant increase in tissue TNF- $\alpha$ compared to the control untreated group. Administration of each of lactulose or minocycline to normal rats produced non-significant effect on tissue TNF- $\alpha$ compared to the control untreated group. Administration of each of lactulose or minocycline to TNBS-treated rats induced significant decrease in tissue TNF- $\alpha$ compared to the group that received TNBS alone. The decrease in tissue TNF- $\alpha$ was significant in minocycline/lactulose combination group compared to the use of either minocycline or lactulose alone (Table 3).

Effect of different treatments on tissue NO

Administration of TNBS to rats resulted in significant increase in tissue NO compared to the control untreated group. Administration of each of lactulose or minocycline to normal rats produced non-significant effect on tissue NO compared to the control untreated group. Administration of each of lactulose or minocycline induced significant decrease in tissue NO compared to the group that received TNBS alone. The decrease in tissue NO was significant in minocycline/lactulose combination group compared to the use of either minocycline or lactulose alone (Table 3).

Effect of different treatments on tissue MPO

Administration of TNBS to rats resulted in significant increase in tissue MPO compared to the control untreated group. Administration of each of lactulose or minocycline to normal rats produced non-significant effect on tissue MPO compared to the control untreated group. Administration of each of lactulose or minocycline induced significant decrease in tissue MPO compared to the group that received TNBS alone. The decrease in tissue MPO was significant in minocycline/lactulose combination group compared to the use of either minocycline or lactulose alone (Table 3).

Table 3: Effect of different treatments on tissue tumor necrosis factor alpha (TNF- $\alpha$ ), myeloperoxidase (MPO), nitric oxide (NO), malondialdehyde (MDA), reduced glutathione (GSH) and histological disease score.

\begin{tabular}{|c|c|c|c|c|c|c|c|}
\hline & $\begin{array}{c}\text { Group I } \\
\text { Control } \\
\text { untreated }\end{array}$ & $\begin{array}{l}\text { Group II } \\
\text { TNBS }\end{array}$ & $\begin{array}{c}\text { Group III } \\
\text { TNBS+ } \\
\text { Lactulose }\end{array}$ & $\begin{array}{l}\text { Group IV } \\
\text { Lactulose }\end{array}$ & $\begin{array}{c}\text { Group V } \\
\text { TNBS+ } \\
\text { minocycline }\end{array}$ & $\begin{array}{c}\text { Group VI } \\
\text { Minocycline }\end{array}$ & $\begin{array}{c}\text { Group VII } \\
\text { TNBS+ } \\
\text { Minocycline } \\
\text { + Lactulose }\end{array}$ \\
\hline $\begin{array}{l}\text { Tissue TNF- } \alpha \\
(\mathrm{pg} / \mathrm{mg} \\
\text { protein) }\end{array}$ & $82.33 \pm 5.55$ & $235.63 \pm 8.6^{\mathrm{a}}$ & $161.3 \pm 5.4^{b}$ & $89.13 \pm 6.2$ & $153.12 \pm 5.1^{b}$ & $86.17 \pm 5.9$ & $109.6 \pm 6.4^{\mathrm{bcd}}$ \\
\hline $\begin{array}{l}\text { Tissue MPO } \\
\text { (U/g tissue) }\end{array}$ & $70.2 \pm 1.67$ & $177.1 \pm 2.8^{\mathrm{a}}$ & $131.6 \pm 2.2^{b}$ & $73.5 \pm 1.8$ & $125.4 \pm 3.15^{b}$ & $76.4 \pm 2.01$ & $92.41 \pm 2.7^{\text {bcd }}$ \\
\hline $\begin{array}{l}\text { Tissue NO } \\
(\mu \mathrm{mol} / \mathrm{g} \\
\text { protein })\end{array}$ & $1.14 \pm 0.07$ & $3.66 \pm 0.08^{\mathrm{a}}$ & $2.57 \pm 0.05^{b}$ & $1.15 \pm 0.07$ & $2.41 \pm 0.06^{b}$ & $1.17 \pm 0.08$ & $1.65 \pm 0.06^{\mathrm{bcd}}$ \\
\hline $\begin{array}{l}\text { Tissue MDA } \\
\text { (nmol/g tissue) }\end{array}$ & $16.04 \pm 0.7$ & $40.91 \pm 0.88^{\mathrm{a}}$ & $26.11 \pm 0.5^{b}$ & $15.62 \pm 0.6$ & $25.13 \pm 0.82^{b}$ & $14.91 \pm 0.6$ & $20.62 \pm 0.5^{\text {bcd }}$ \\
\hline $\begin{array}{l}\text { Tissue GSH } \\
(\mu \mathrm{mol} / \mathrm{g} \\
\text { tissue) }\end{array}$ & $1.93 \pm 0.05$ & $0.84 \pm 0.04^{\mathrm{a}}$ & $1.37 \pm 0.05^{b}$ & $1.88 \pm 0.04$ & $1.42 \pm 0.06^{b}$ & $1.9 \pm 0.05$ & $1.67 \pm 0.04^{\text {bcd }}$ \\
\hline $\begin{array}{l}\text { Histological } \\
\text { disease score }\end{array}$ & 0.00 & $1.36 \pm 0.03^{\mathrm{a}}$ & $0.75 \pm 0.02^{b}$ & 0.00 & $0.69 \pm 0.01^{b}$ & 0.00 & $0.44 \pm 0.02^{\text {bcd }}$ \\
\hline
\end{tabular}

${ }^{\text {a }}$ Significant compared to the control untreated group

b Significant compared to TNBS group

${ }^{\mathrm{c}}$ Significant compared to TNBS+lactulose group

${ }^{\mathrm{d}}$ Significant compared to TNBS + minocycline group

\section{Histopathological results}

Administration of TNBS to rats resulted in significant increase in the histological disease score compared to the control group. Administration of each of lactulose or minocycline to normal rats produced non-significant effect on the histological disease score compared to the control 
untreated group. Administration of each of lactulose or minocycline to rats that received TNBS induced significant decrease in the histological disease score with significant decrease in the apoptotic index compared to the group that received TNBS alone. The decrease in the histological disease score and the decrease in the apoptotic index were significant in minocycline/lactulose combination group compared to the use of either minocycline or lactulose alone (Table 3, Table 4, Fig. 2).

Table 4: The effect of different treatments on the apoptotic index in the studied groups.

\begin{tabular}{cc} 
Group & Apoptotic index (\%) \\
\hline Normal control & $1.4 \pm 0.07$ \\
TNBS & $8.2 \pm 0.41^{\mathrm{a}}$ \\
TNBS + Lactulose & $5.7 \pm 0.12^{\mathrm{b}}$ \\
Lactulose & $1.6 \pm 0.08$ \\
TNBS + Minocycline & $4.8 \pm 0.21^{\mathrm{b}}$ \\
Minocycline & $1.54 \pm 0.07$ \\
TNBS + Minocycline + Lactulose & $2.8 \pm 0.3^{\mathrm{bcd}}$
\end{tabular}

Apoptotic index (\%) was calculated for sections of the colon (values presented as the mean \pm SEM of an average of 10 fields).

${ }^{a}$ Significant compared to the control untreated group

${ }^{\mathrm{b}}$ Significant compared to TNBS group

${ }^{\mathrm{c}}$ Significant compared to TNBS + lactulose group

${ }^{\mathrm{d}}$ Significant compared to TNBS + minocycline group

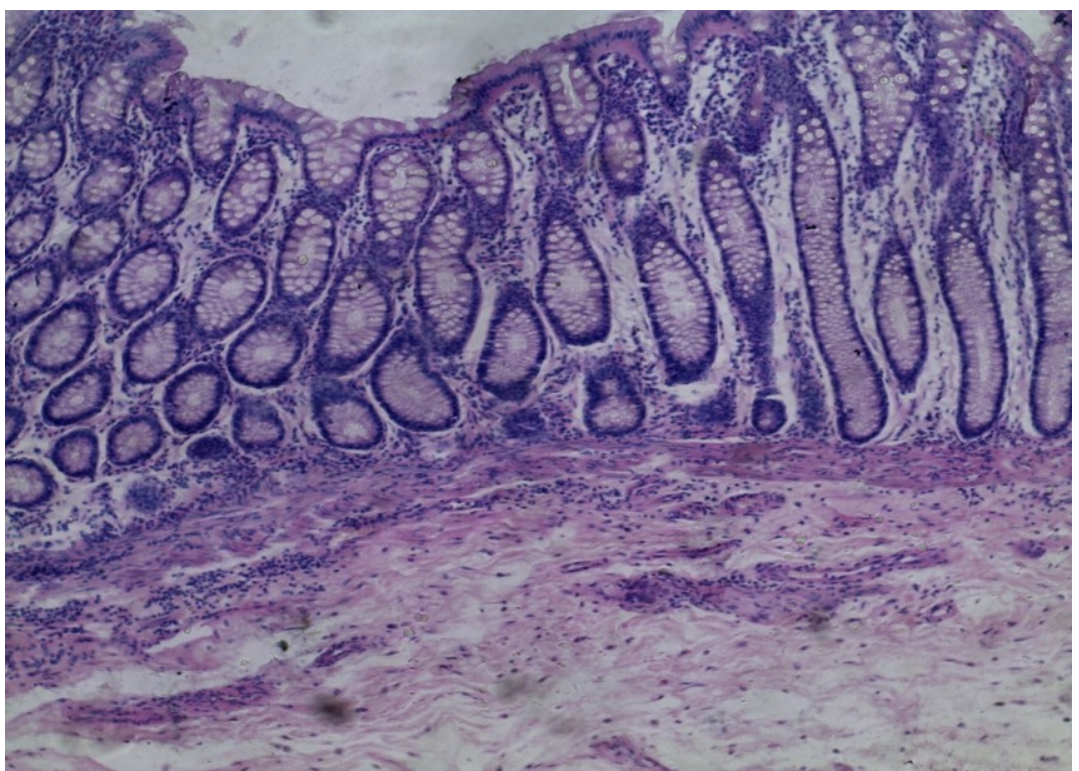

Fig. 2. A: H\&E stained sections from the colon of the control group with normal colonic mucosa, intact epithelium, normal goblet cell population and minimal mononuclear cellular infiltration in the lamina propria. 


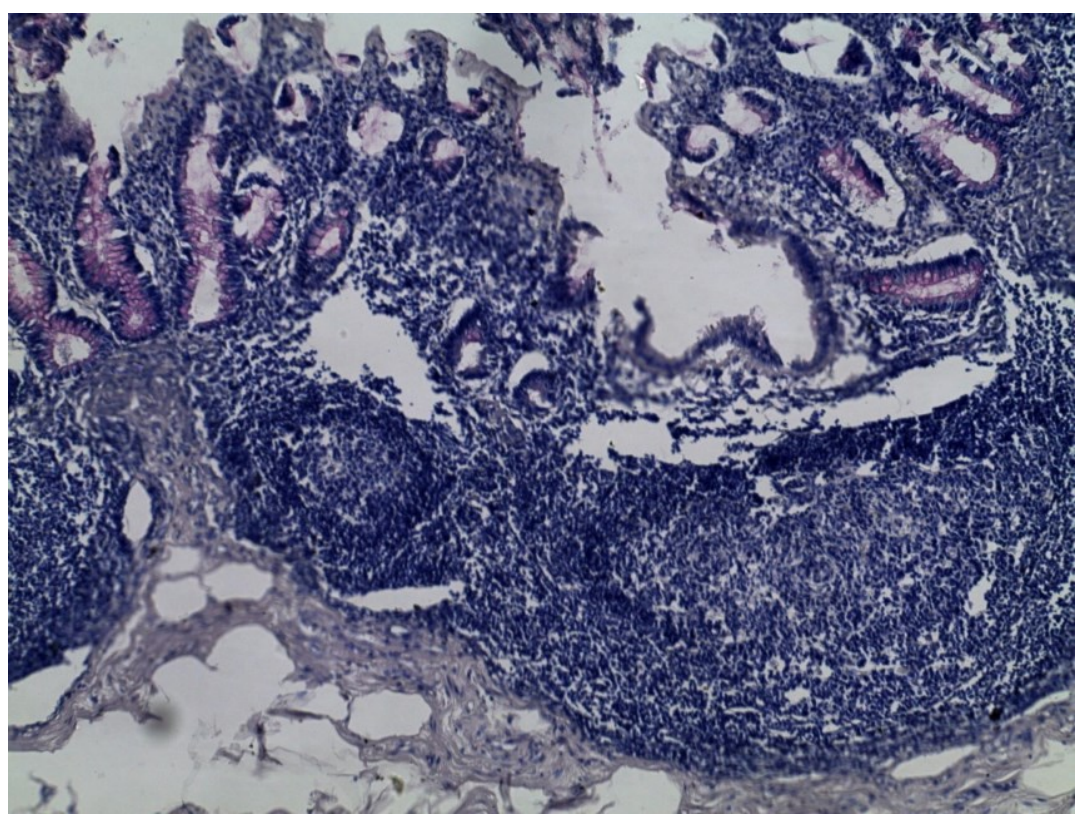

Fig. 2. B: H\&E stained sections from the colon of TNBS-treated group with mucosal ulceration, dense mononuclear cellular infiltration in the lamina propria with destroyed crypts and mucosal glands.

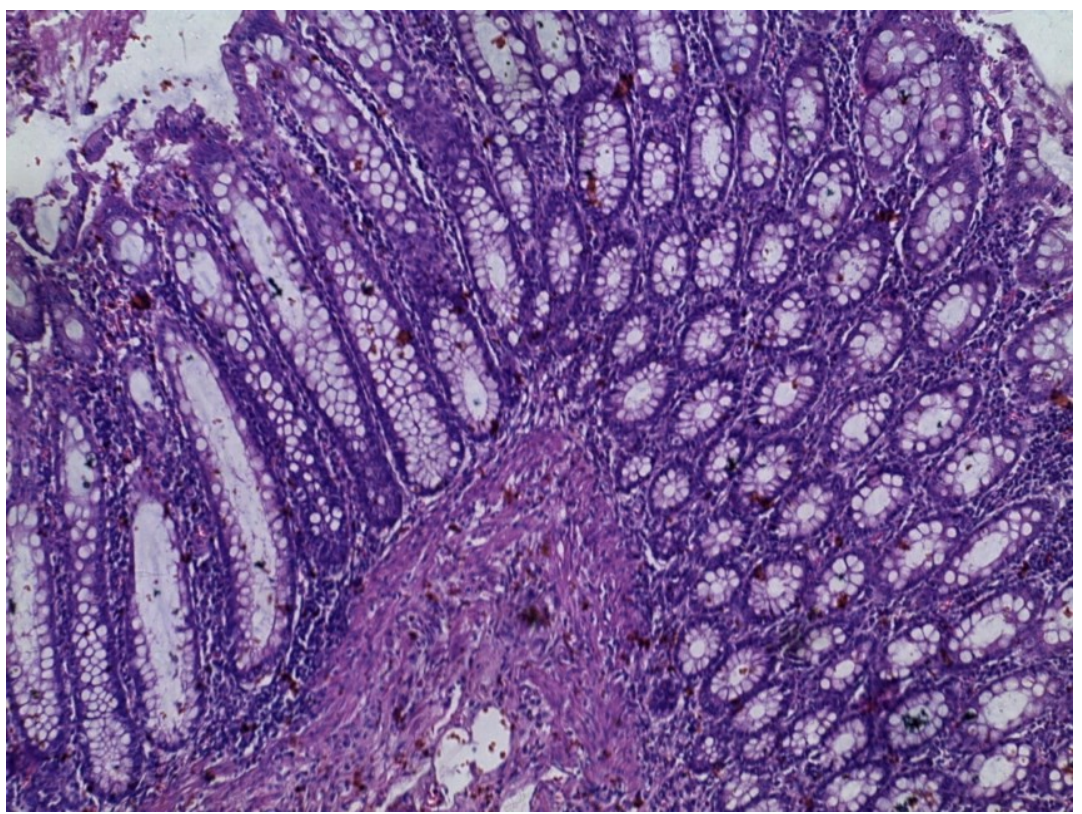

Fig. 2. C: H\&E stained sections from the colon of TNBS+ lactulose treated group showing minimal mucosal ulceration, increased goblet cell population, moderate inflammatory cellular infiltration with congested submucosal blood vessels. 


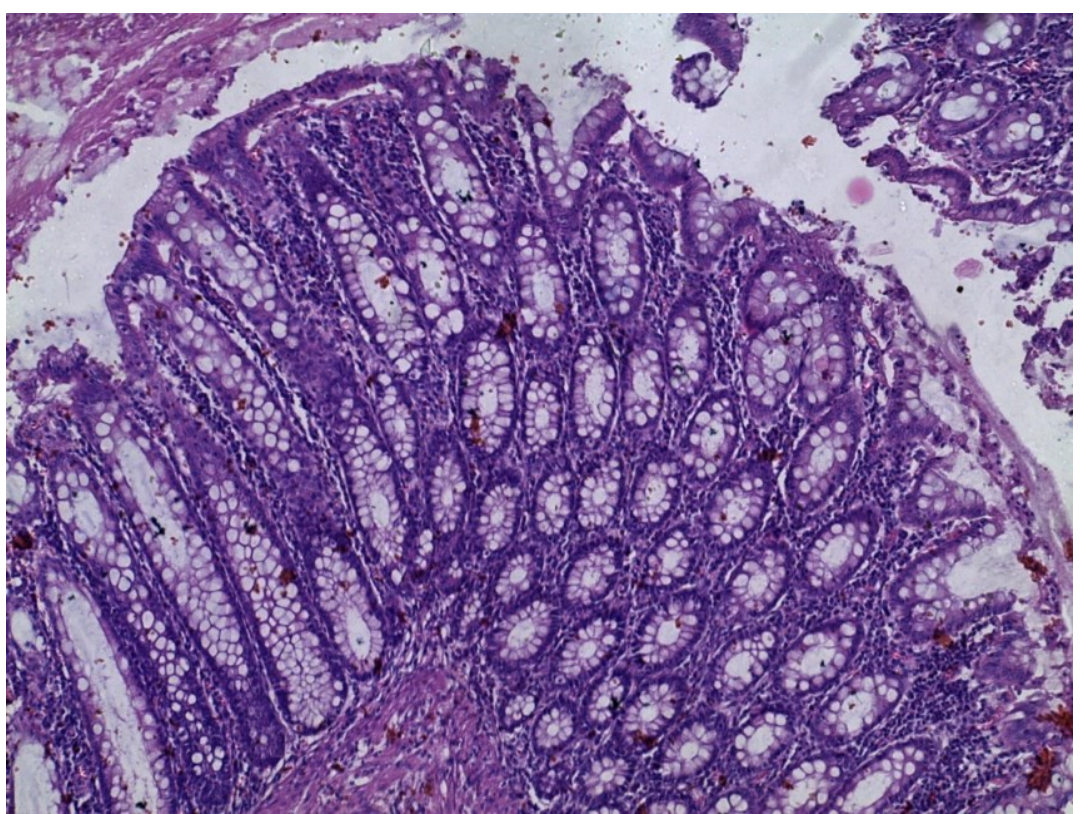

Fig. 2. D: H\&E stained sections from the colon of the control group that received lactulose with normal appearance of the colonic mucosa, intact epithelium and normal goblet cells.

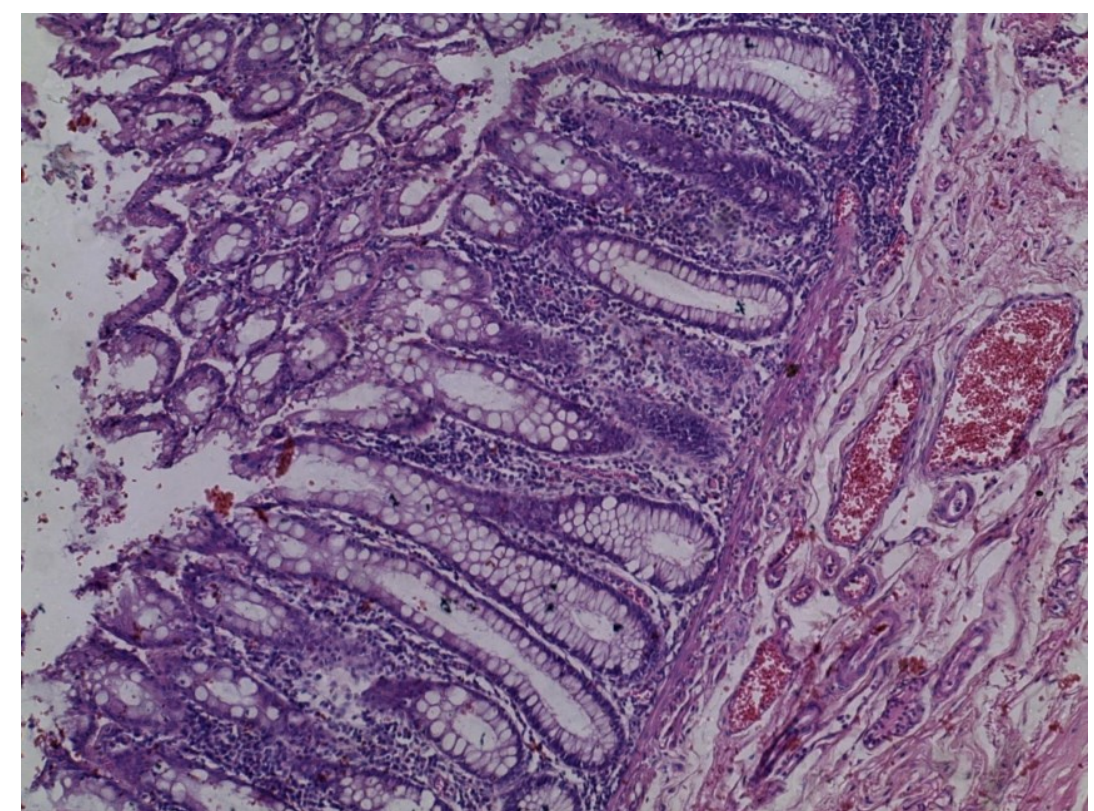

Fig. 2. E: H\&E stained sections from the colon of TNBS+minocycline treated group showing intact mucosal surface, increased goblet cell population, mild to moderate inflammatory cellular infiltration with congested submucosal blood vessels. 


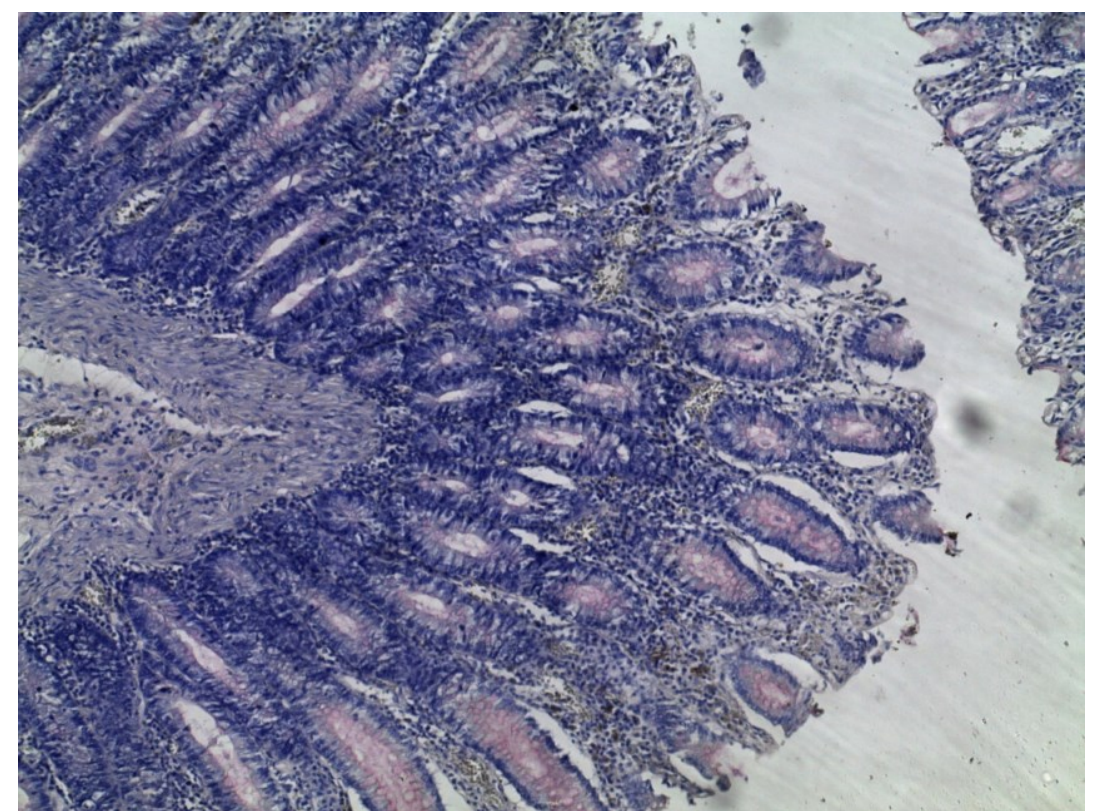

Fig. 2. F: H\&E stained sections from the colon of the control group that received minocycline with apparently normal colonic mucosa, intestinal epithelium and normal goblet cells with minimal cellular infiltration.

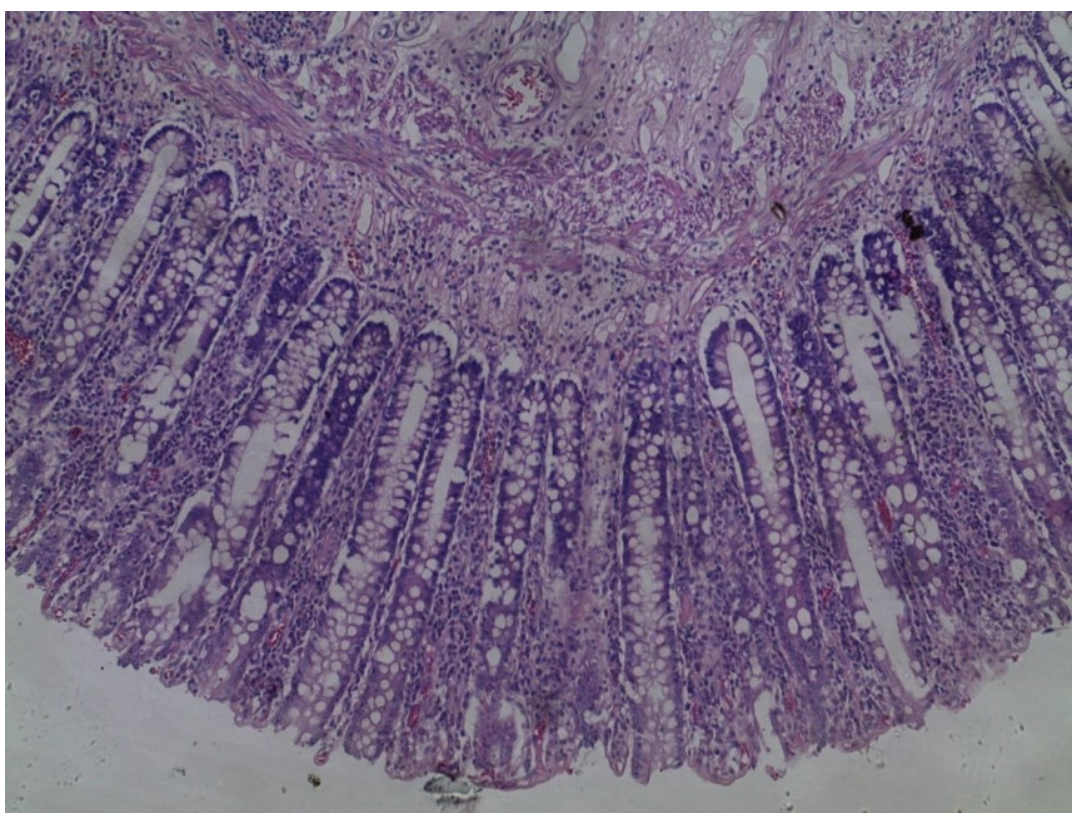

Fig. 2. G: H\&E stained sections from the colon of TNBS + minocycline + lactulose treated group showing apparently normal mucosal glands and crypts with mild inflammatory cellular infiltration.

\section{Discussion}

Colitis is a non-specific inflammatory disorder primarily involving the mucosa and submucosa of the colon. The exact etiology of colitis is still not completely understood. However, several factors were suggested to be involved in the pathogenesis of colitis such as overgrowth of pathogenic microorganisms, overproduction of pro-inflammatory cytokines, formation of reactive oxygen species (ROS) and neutrophil infiltration [4]. Many compounds had been reported to induce colitis in animals such as dextran sodium sulphate (DSS) and TNBS [1]. TNBS is a hapten, when it is bound with tissue proteins of high molecular weight, it will turn into an antigen. It has been shown that it can elicit immunologic responses, enhance formation of pro-inflammatory cytokines such as prostaglandin E2, thromboxane B2, leukotriene B4, platelet activating factor and interleukins, increase production of free radicals and induce generation of colitis [16] which was in 
agreement with the results of the present study where administration of TNBS to rats resulted in significant decrease in tissue GSH with significant increase in DAI, tissue TNF- $\alpha$, MDA, NO, MPO and the histological disease score compared to the untreated control group.

Recent studies point to an over stimulation or inadequate regulation of the mucosal immune system as a major pathophysiologic pathway of colitis and particular emphasis has been given to the study of mucosal inflammation or immunologic reactions $[10,24]$. When the disease is active, the lamina propria of the mucosa becomes heavily infiltrated with inflammatory cells with increased mucosal IgG production, evidence of complement activation and activation of macrophages and $\mathrm{T}$ cells. This immunological activity is associated with the release of inflammatory cytokines, kinins, leukotrienes, platelet activating factor and ROS. These mediators not only amplify the immune and inflammatory response, but also have direct effects on epithelial function, on endothelial function and on repair mechanisms, thus increasing collagen synthesis. In addition, many of the cytokines (interleukins 1 and $6, \mathrm{TNF}-\alpha$ ) will activate an acute phase response, resulting in fever and a rise in serum acute phase proteins [4].

Lactulose is a synthetic sugar used in treatment of constipation and hepatic encephalopathy. It has been reported that lactulose has prebiotic, antioxidant and anti-inflammatory properties which may ameliorate colonic inflammation $[9,10]$. These studies were in agreement with the results of the present work where administration of lactulose to rats resulted in significant increase in tissue GSH with significant decrease in DAI, tissue TNF- $\alpha$, MDA, NO, MPO and the histological disease score compared to TNBS-treated group.

Since lactulose has prebiotic action, it can be used by probiotics (Lactobacilli, Bifidobacteria) to promote their growth and survival in the colon. Lactulose is metabolized by the intestinal microflora to lactate and other organic acids with concomitant reduction in luminal $\mathrm{pH}$ which may decrease the growth of pathogenic bacteria [9]. Also, lactulose may induce the growth and activity of Bifidobacteria and Lactobacilli which secrete inhibitory products having antimicrobial activity against potential pathogens and enhance the synthesis of secretory immunglobulin A to microbial pathogens. This may lead to significant increase in tissue levels of the antiinflammatory cytokine interleukin 10 , together with the decrease in proinflammatory cytokines such as TNF- $\alpha$ which plays a key role in the pathogenesis of colitis [25].

One of the main byproducts of lactulose is the molecular hydrogen $\left(\mathrm{H}_{2}\right)$. Recently, experimental evidences have documented that $\mathrm{H}_{2}$ possesses the ability to selectively neutralize ROS which can damage cellular macromolecules aggressively and inhibit iNOS which plays an important role in the development of colonic inflammation. Moreover, $\mathrm{H}_{2}$ mediates suppression of proinflammatory cytokines, especially TNF- $\alpha$ and IL-6 in the inflammed tissues. As a novel antioxidant, $\mathrm{H}_{2}$ can easily penetrate biomembranes and diffuse into the cytosol, mitochondria and nucleus without affecting the normal intestinal flora [10].

Minocycline is a semi-synthetic second generation tetracycline antibiotic. It has been shown to have anti-apoptotic, immunosuppressive, antioxidant and anti-inflammatory properties in several pathological conditions such as acne vulgaris, rheumatoid arthritis, bronchial asthma, neurological diseases and inflammatory bowel disease $[13,15,26]$ which was in the same line with the results of the present study where administration of minocycline to rats resulted in significant increase in tissue GSH with significant decrease in DAI, tissue TNF- $\alpha$, MDA, NO, MPO and the histological disease score compared to TNBS-treated group.

The immunological activity of minocycline was proven by its remarkable effect in restoring balanced intestinal microorganisms. In colitis, a significant increase in enterobacteria in comparison with the healthy rats was observed, and these were significantly downregulated by minocycline, thus reducing the bacterial load in the intestinal mucosa and contributing to the amelioration of the inflammatory response [27]. Minocycline was reported to increase the counts of lactobacilli and bifidobacteria, which positively affect the intestinal barrier function by decreasing mucosal permeability and are able to modulate the immune response [28]. The impairment in the epithelial barrier function is considered as one of the initial steps in intestinal inflammation as it may facilitate the access of antigens from the intestinal lumen, triggering the exacerbated immune response. 
Minocycline was found to preserve the mucus-secreting layer that covers the epithelium and acts as a physical barrier protecting its integrity [29].

Garrido-Mesa et al. [13] found that minocycline has anti-inflammatory effect both histologically, associated with a reduction in the inflammatory infiltrate, and biochemically, by reduction of the main pro-inflammatory cytokines involved in the pathogenesis of colitis. The antiinflammatory effect exerted by minocycline in experimental colitis cannot only be explained by a modulation of the intestinal microorganisms, but also by its ability to decrease TNF- $\alpha$ and IL-17 production which play a key role in the development of intestinal inflammation [3]. Szeto et al. [30] reported that minocycline inhibits apoptosis via attenuation of TNF- $\alpha$ and downregulating the proinflammatory cytokine output. This effect is mediated by a direct action of minocycline on the activated $\mathrm{T}$ cells which impairs cytokine production and blocks nuclear factor-kappa $\mathrm{B}$ translocation. Moreover, minocycline was found to inhibit colonic iNOS expression in the inflamed intestine, thus avoiding the deleterious effect that $\mathrm{NO}$ overproduction may exert on the colonic tissue in these intestinal conditions [31]. Also, minocycline was reported to improve the colonic oxidative status, decrease lipid peroxidation and modulate the expression of different chemotactic mediators in the inflammed tissues [15].

In the present study, the decrease in DAI, tissue NO, MDA, TNF- $\alpha$ and MPO with the increase in tissue GSH were significant in minocycline/lactulose combination group compared to TNBS-treated rats that received either minocycline or lactulose alone. This might be due to the synergistic anti-inflammatory and antioxidant properties of minocycline/lactulose combination together with their ability to inhibit pathogenic organisms in the colon and induce apoptosis.

\section{Conclusion}

The present study demonstrated that lactulose and minocycline have protective effect on TNBS-induced colitis in rats due to their anti-inflammatory and antioxidant properties together with their inhibitory effects on the pathogenic organisms in the colon with induction of apoptosis but minocycline/lactulose combination had the upper hand. So, it is recommended to use minocycline/lactulose combination as an adjuvant agent in treatment of colitis due to their high efficacy and less side effects.

\section{Acknowledgement}

Many thanks to Prof. Dr. Karima El-Desouky, Pathology Department, Faculty of Medicine, Tanta University, Egypt for her kind help in the histopathological study.

\section{References}

[1] Y. Liu, X.Y. Wang, X. Yang, S. Jing, L. Zhu, S.H. Gao, Lung and intestine: a specific link in an ulcerative colitis rat model, Gastroenterol. Res. Pract. 2013 (2013) 124530.

[2] K.H. Morsy, A.F. Hasanain, Hepatobiliary disorders among naïve patients with ulcerative colitis in Upper Egypt, Arab. J. Gastroenterol. 13 (2012) 71-76.

[3] M. Sarra, F. Pallone, T.T. Macdonald, G. Monteleone, IL-23/IL-17 axis in IBD. Inflamm Bowel Dis (2010) 1808-1813.

[4] J. Yao, J.Y. Wang, L. Liu, Y.X. Li, A.Y. Xun, W.S. Zeng, C.H. Jia, X.X. Wei, J.L. Feng, L. Zhao, L.S. Wang, Anti-oxidant effects of resveratrol on mice with DSS-induced ulcerative colitis, Arch. Med. Res. 41 (2010) 288-294.

[5] B. Karakoyun, U. Uslu, F. Ercan, M.S. Aydin, M. Yuksel, A.V. Ogunc, I. Alican, The effect of phosphodiesterase-5 inhibition by sildenafil citrate on inflammation and apoptosis in rat experimental colitis, Life Sciences 89 (2011) 402-407.

[6] R.C. Langan, P.B. Gotsch, M.A. Krafczyk, D.D. Skillinge, Ulcerative colitis: diagnosis and treatment, American family physician 76 (2007) 1323-1330. 
[7] S.J. Gardiner, E.J. Begg, Pharmacogenetics, Drug-Metabolizing Enzymes, and Clinical Practice, Pharmacological Reviews 58 (2006) 521-590.

[8] B. Medhi, A. Prakash, P.K. Avti, U.N. Saikia, P. Pandhi, K.L. Khanduja, Effect of Manuka honey and sulfasalazine in combination to promote antioxidant defense system in experimentally induced ulcerative colitis model in rats, Indian J. Exp. Biol. 46 (2008) 583-590.

[9] G. Rumi, R. Tsubouchi, M. Okayama, S. Kato, G. Mózsik, K. Takeuchi, Protective effect of lactulose on dextran sulfate sodium-induced colonic inflammation in rats, Digestive Diseases and Sciences 49 (2004) 1466-1472.

[10] X. Chen, Q. Zuo, Y. Hai, X.J. Sun, Lactulose: an indirect antioxidant ameliorating inflammatory bowel disease by increasing hydrogen production, Med. Hypotheses 76 (2011) 325327.

[11] B.M. Buchholz, D.J. Kaczorowski, R. Sugimoto, R. Yang, Y. Wang, T.R. Billiar, K.R. McCurry, A.J. Bauer, A. Nakao, Hydrogen inhalation ameliorates oxidative stress in transplantation induced intestinal graft injury, Am. J. Transplant. 8 (2008) 1-10.

[12] M. Kajiya, M.J. Silva, K. Sato, K. Ouhara, T. Kawai, Hydrogen mediates suppression of colon inflammation induced by dextran sodium sulfate, Biochem. Biophys. Res. Commun. 386 (2009) $11-15$.

[13] N. Garrido-Mesa, D. Camuesco, B. Arribas, M. Comalada, E. Bailón, M. Cueto-Sola, P. Utrilla, A. Nieto, A. Zarzuelo, M.E. Rodríguez-Cabezas, J. Gálvez, The intestinal anti-inflammatory effect of minocycline in experimental colitis involves both its immunomodulatory and antimicrobial properties, Pharmacol. Res. 63 (2011) 308-319.

[14] T.Y. Huang, H.C. Chu, Y.L. Lin, C.K. Lin, T.Y. Hsieh, W.K. Chang, Y.C. Chao, C.L. Liao, Minocycline attenuates experimental colitis in mice by blocking expression of inducible nitric oxide synthase and matrix metalloproteinases, Toxicol. Appl. Pharmacol. 237 (2009) 69-82.

[15] R.L. Kraus, R. Pasieczny, K. Lariosa-Willingham, M.S. Turner, A. Jiang, J.W. Trauger, Antioxidant properties of minocycline: neuroprotection in an oxidative stress assay and direct radical-scavenging activity. J Neurochem 94 (2005) 819-827.

[16] L. Zheng, Z.Q. Gao, S.X. Wang, A chronic ulcerative colitis model in rats, World J. Gastroenterol. 6 (2000) 150-152.

[17] H.S. Cooper, S.N. Murthy, R.S. Shah, D.J. Sedergran, Clinicopathologic study of dextran sulfate sodium experimental murine colitis, Lab Invest 1993; 69:238-249.

[18] I. Hirata, S. Yasumoto, K. Toshina, T. Inoue, T. Nishikawa, N. Murano, M. Murano, F.Y. Wang, K. Katsu, Evaluation of the effect of pyrrolidine dithiocarbamate in suppressing inflammation in mice with dextran sodium sulfate-induced colitis, World J. Gastroenterol. 13 (2007) 1666-1671.

[19] G. Aykaç, M. Uysal, A.S. Yalçin, N. Koçak-Toker, A. Sivas, H. Öz, The effect of chronic ethanol ingestion on hepatic lipid peroxide, glutathione, glutathione peroxidase and glutathione transferase in rats, Toxicol. 36 (1985) 71-76.

[20] A.F. Casini, M. Ferrali, A. Pompella, E. Maellaro, M. Comporti, Lipid peroxidation and cellular damage in extrahepatic tissues of bromobenzene-intoxicated mice, Am. J. Pathol. 123 (1986) 520-531.

[21] P.P. Bradley, D.A. Priebat, R.D. Christensen, G. Rothstein, Measurement of Cutaneous Inflammation: Estimation of Neutrophil Content with an Enzyme Marker, J. Invest. Dermatol. 78 (1982) 206-209.

[22] N. Cortas, N.W. Wakid, Determination of inorganic nitrate in serum and urine by a kinetic cadmium-reduction method, Clin. Chem. 36 (1990) 1440-1443.

[23] Lowry OH, Rosebrough, NJ, Farr AL , Randall RJ. Protein measurement with Folin phenol reagent. J Biol Chem 1951; 193: 265-275.

[24] Yue-Meng W, You-Qing Z, Bing X, Jun L. Treating TNBS-Induced colitis in rats with probiotics. Turk J Gastroenterol 2011; 22: 486-493. 
[25] S. Ulisse, P. Gionchetti, S. D’Alo, F.P. Russo, I. Pesce, G. Ricci, F. Rizzello, U. Helwig, M.G. Cifone, M. Campieri, C. De Simone, Expression of cytokines, inducible nitric oxide synthetase and matrix metalloproteinases in pouchitis: effects of probiotic treatment, Am. J. Gastroenterol. 96 (2001) 2691-2699.

[26] A.N. Sapadin, R. Fleischmajer, Tetracyclines: nonantibiotic properties and their clinical implications, J. Am. Acad. Dermatol. 54 (2006) 258-265.

[27] L. Peran, S. Sierra, M. Comalada, F. Lara-Villoslada, E. Bailon, A. Nieto, A. Concha, M. Olivares, A. Zarzuelo, J. Xaus, J. Gálvez, A comparative study of the preventative effects exerted by two probiotics Lactobacillus reuteri and Lactobacillus fermentum, in the trinitrobenzenesulfonic acid model of rat colitis, Br. J. Nutr. 97 (2007) 96-103.

[28] N. Borruel, M. Carol, F. Casellas, M. Antolín, F. de Lara, E. Espín, J. Naval, Guarner F., Malagelada JR. Increased mucosal tumour necrosis factor alpha production in Crohn's disease can be downregulated ex vivo by probiotic bacteria. Gut 2002; 51: 659-664.

[29] L. Su, L. Shen, D.R. Clayburgh, S.C. Nalle, E.A. Sullivan, J.B. Meddings, C. Abraham, J.R.. Turner, Targeted epithelial tight junction dysfunction causes immune activation and contributes to development of experimental colitis, Gastroenterol. 136 (2009) 551-563.

[30] G. Szeto, A. Brice, H. Yang, S. Barber, R. Siliciano, J. Clements, Minocycline attenuates HIV infection and reactivation by suppressing cellular activation in human CD4+ T cells, The Journal of infectious diseases 201 (2010) 1132-1140.

[31] K.P. Pavlick, F.S. Laroux, J. Fuseler, R.E. Wolf, L. Gray, J. Hoffman, M.B. Grisham, Role of reactive metabolites of oxygen and nitrogen in inflammatory bowel disease, Free Radic. Biol. Med. 33 (2002) 311-322. 